\title{
Martin Codax y las cantigas de santuario gallegoportuguesas
}

\author{
Martin Codax and the Galician Portuguese \\ cantigas de santuario
}

Santiago Gutiérrez García

Universidad de Santiago de Compostela

santiago.gutierrez@usc.es

ORCID iD: https://orcid.org/0000-0001-6005-9248

\begin{abstract}
RESUMEN: El presente artículo estudia las cantigas de amigo gallegoportuguesas que se conocen como "cantigas de santuario", atendiendo a sus condiciones de producción y recepción como claves para acceder a su significado. Se cuestiona la relación existente entre el autor y el templo aludido en la cantiga, para lo cual se adoptan como objeto de estudio a Martin Codax y sus siete cantigas de amigo. Para ello se analizan el posible origen toponímico de su apellido y la relación que mantiene con Vigo, el lugar que se menciona en sus cantigas.
\end{abstract}

Palabras clave: Lírica gallegoportuguesa, cantigas de amigo, cantigas de santuario, Martin Codax, Vigo.

ABSTRACT: This article studies the Galician-Portuguese cantigas known as cantigas de santuario, arguing that their conditions of production and reception are crucial to their interpretation. It is questioned the relationship between sanctuaries and poets, using Martin Codax and his seven cantigas de amigo as a case study. To do this, it is analysed the possible toponimic origin of his surname and his relationships with Vigo, the town he alludes to in his cantigas.

Keywords: Galician-Portuguese Lyric, cantigas de amigo, cantigas de santuario, Martin Codax, Vigo. 


\section{Preliminares. CANTigas de SANTUARio}

El corpus lírico gallegoportugués ofrece un conjunto de composiciones ${ }^{1}$ que la crítica ha denominado "cantigas de romaría" o, con más propiedad, "cantigas de santuario", a las que tradicionalmente se les ha concedido la categoría de subgénero $^{2}$, dentro del macrogénero de las cantigas de amigo. La atribución de esta condición genérica derivaba, en última instancia, de los principios de homogeneidad estilística que se suelen emplear en el análisis de la lírica trovadoresca gallegoportuguesa, los cuales conducen a que se identifique una categoría textual - a menudo elevada a la condición genérica o, en su defecto, a la de modalidad discursiva en el seno de un género- a partir de la existencia de una invariante formal o estilística. No obstante, los desajustes metodológicos a los que da lugar un modelo de análisis como el citado ${ }^{3}$ llevan a un auténtico proceso de reificación, según el cual se procura adecuar los textos a las exigencias que impone una etiqueta previa.

En el caso que ahora nos ocupa, dicho rasgo común lo constituiría la presencia de un hagiotopónimo, correspondiente a un templo en el que se sitúa la acción relatada en la composición. A partir de esa marca geográfica, por lo demás explicable desde el topos de la ambientación naturalística de las cantigas de amigo, la crítica ha adjudicado a estas piezas una serie de características de comprobación menos segura, como que son obra de un juglar de origen gallego, quien tomaría el apellido de la comarca o la localidad en la que se asienta dicho santuario; la ubicación de ese mismo templo en Galicia o el norte de Portugal; o su condición de centro de devoción secundario, correspondiente a una ermita apartada de las grandes rutas de peregrinación o de centros de población importantes. Desde el punto de vista extrínseco, se ha supuesto que la utilización por parte de dichos juglares del citado topónimo obedecía a un propósito propagandístico, por medio del cual se buscaba la promoción de las reliquias depositadas en tales templos o de las romerías que en ellos se celebraban — de ahí la denominación ya aludida de cantigas de romaría - (vid., por ejemplo, Brea y Lorenzo, 1998: 261; Correia, 1993: 14 y sigs.; Tavani, 1986: 142 y 1992: 37-38).

Ahora bien, la aparente uniformidad de este conjunto textual revela no pocas objeciones a las características generales que se acaban de exponer, descu-

\footnotetext{
${ }^{1}$ Los diversos autores que se han acercado a las cantigas de santuario no coinciden a la hora de fijar el número de piezas que conforman su corpus textual. La disparidad de propuestas se mueve entre las cincuenta y las ochenta piezas. Vid. Asensio (1970: 29), Brea (1999), Correia (1993: 22), Michäelis de Vasconcelos (1905: 879), Monteagudo (1998: 125-127) y Tavani (1986: 143).

2 Sobre la especificidad textual de tales composiciones y las posturas dispares que suscitan, vid. Brea y Lorenzo (1998: 256-261), Correia (1993: 11-12), Ferreira (1997: 44), Michäelis de Vasconcelos (1905: 879), Monteagudo (1998: 100-102) y Tavani (1986: 142-143).

${ }^{3}$ Sobre los cuales tratamos más por extenso en Gutiérrez García (2010).
} 
briendo una realidad muy compleja sobre la que aún quedan cuestiones por explicar. La más evidente afecta a la propia interpretación de los textos, ya que no está clara la vocación propagandística de muchas de estas composiciones. De esta manera, a menudo la mención escueta a un santuario no sólo no va asociada a la de la correspondiente romería, sino que queda relegada a la condición de rasgo estilístico secundario, en la medida en que se ve sumida en la red de referencias poéticas de la cantiga de amigo, con lo que prima en ellas el tono lírico-amoroso por encima del religioso-promocional ${ }^{4}$.

Ligada a la anterior estaría la cuestión de la autoría. A pesar de que se observa un núcleo de escritores adscribibles a la sección cancioneril que Oliveira (1994 y 2001) denomina cancioneiro de xograres galegos, ni todos los cultivadores de la poesía de santuario pertenecen a este grupo ni, no menos importante, los que sí lo son responden en su totalidad a las condiciones de producción que les ha adjudicado la crítica. En efecto, a partir de los datos incompletos que se pueden extraer de este tipo de cantigas, se ha supuesto que dichos juglares mantenían vínculos directos con los centros de devoción a los que aluden en sus composiciones, de manera que estos indicaban su lugar de nacimiento. El indicio más claro de que se dispone al respecto lo constituye el apellido de tales autores, por lo común de tipo geográfico, que en ocasiones coincide con el nombre de la comarca en la que se sitúa el citado santuario. La ligazón entre los centros religiosos y el lugar de procedencia de los respectivos autores se ha visto reforzada por la fidelidad que estos muestran hacia aquellos, de tal manera que cada poeta menciona un solo templo en su producción lírica y, a la inversa, cada santuario, sólo es cantado por un autor ${ }^{5}$. Así, entre los casos más conocidos se encuentran Johan de Cangas, cantor de la ermita de San Mamede, en Beluso, no lejos de Cangas do Morrazo, villa de la que habría tomado el cognomen; o Johan de Requeixo, que menciona el templo de Santa María do Faro, en los alrededores de Chantada, a la vez que adopta su apellido de una aldea cercana a esta última localidad ${ }^{6}$.

No obstante, la adopción como norma de este sistema de filiación entraña graves riesgos, debido tanto a que existen numerosas lagunas documentales en

\footnotetext{
${ }^{4}$ Con todo, vid. Correia (1993: 17) y Tavani (1986: 142), quienes matizan la importancia del componente devocional de estas cantigas.

${ }^{5}$ De ahí que a los poetas de santuario se les haya denominado como verdaderos "cantores oficiales" de los respectivos templos (Gonçalves, 1986: 48). De la importancia que asume el santuario como tema poético, con proyección propagandística, en la lírica gallego portuguesa son un buen exponente las Cantigas de Santa María, tal y como se recoge en Filgueira Valverde (1958)

${ }^{6}$ Para los nombres de los autores y las reproducción y numeración de sus cantigas seguimos a Brea (1996). Asimismo, para la documentación de los diversos autores hemos tenido presente la información contenida tanto en la citada obra, como en Michaëlis de Vasconcelos (1905), Oliveira (2001: 185-205 y 1994: 303-440), Ron Fernández (2005: 121-188) y Tavani (1986: 277-329).
} 
este ámbito de estudio, como a que no todas las indicaciones geográficas se prestan a derivaciones tan sencillas en apariencia. De este modo, junto a algún ejemplo de autor con apellido patrilineal - como Airas Paez o Sancho Sanchez-, se encuentran otros juglares de los que se desconoce su cognomen - así, Meendinho, Golparro o Lopo-. En ambos casos, todo intento de dilucidar su lugar de procedencia a partir de las alusiones contenidas en su producción poética no deja de ser una hipótesis sometida a serias reservas. Más aún cuando, como acabamos de sugerir, los apellidos toponímicos suscitan tantas dudas como certezas. Tal sucede, sin ir más lejos, con Johan Servando, autor del corpus más amplio de cantigas de santuario que se ha conservado, constituido por diecisiete piezas. Su producción alude con insistencia a la ermita de San Servando, acaso San Servando de Pazos, en Santa María de Barxeles, al sur de la provincia de Ourense. Sin embargo, el afán promocional que demuestra en su obra, unido al hecho de que, por lo que se sabe, desarrolló su carrera poética en la corte de Alfonso X de Castilla, ha llevado a considerar la posibilidad de que adoptase su cognomen como una maniobra más de su programa de promoción y no por haber nacido en la comarca a la que canta (Gonçalves, 1986: 45-49)7. Esta posibilidad cobra fuerza si se tiene en cuenta una circunstancia sobre la que llama la atención Beltran (1987: 9 y 2002: 7 y 14-15): la especialización de ciertos autores en la utilización de determinados motivos o símbolos literarios, que llegan a constituir auténticas marcas de autor —el caso más claro, según este estudioso, serían los ciervos de Pero Meogo, pero también, sin ir más lejos, la ambientación marítima o la mención a Vigo de Martin Codax-. Dicho con otras palabras, el empleo de esos recursos compositivos probablemente sirviesen como mecanismos poéticos de individualización de autores, de manera similar a la especialización de los juglares de santuario al ambientar sus composiciones, a la manera de Johan Servando, en un lugar concreto y sólo en ese.

La mención a la obra de este último juglar descubre otra circunstancia digna de tenerse en cuenta a la hora de establecer la vinculación entre los autores de las cantigas que tratamos y los medios de producción poética en que desarrollaron su labor. Esta no es otra que la presencia documentada de muchos de estos autores en la corte castellana $-\mathrm{y}$ ocasionalmente en la portuguesa-, lo que los sitúa integrados en los grandes círculos de difusión y recepción líricas de la época. Así sucede, por ejemplo, además de con el ya citado Johan Servando, con Lopo, Martin Perez d'Alvim, Airas Nunes o Airas Paez, que se

\footnotetext{
${ }^{7}$ Esta circunstancia y sus posibles implicaciones como mecanismo caracterizador de autores reaparece en Beltran (2002: 6-7 y s. a.), así como en Monteagudo (1998: 109). La ecuación que establece la cercanía física entre un autor y el templo al que alude había llevado a Nunes (1973: I, 332 y III, 685-686), a ubicar la ermita de San Servando en las cercanías de Toledo, debido a la presencia de Johan Servando en la corte del rey Sabio. Esta tesis fue rebatida por Gonçalves (1986: 46-47).
} 
movieron entre las cortes de Fernando III, Sancho IV y Don Denis. De este modo pierde validez la inmediatez necesaria, a la que nos hemos referido, entre el autor y la geografía recreada en su obra y que había llevado a suponer que los poetas de santuario florecían en modestas cortes bajo el patrocinio "dunha pequena nobreza laica de ámbito local” (Monteagudo, 1998: 121). Llegados a este punto no se entiende por qué ha de suponerse que un trovador o un juglar integrado en las grandes cortes reales de la segunda mitad del siglo XIII debe aludir en sus cantigas a los templos de su lugar de nacimiento. O, desde el punto de vista inverso, por qué los medios de promoción literaria interesados en el patrocinio de dichos templos habrían de escoger para tal labor a los autores que hubiesen nacido junto a esas casas de religión, aun a pesar de que floreciesen a cientos de quilómetros de distancia de estas ${ }^{8}$.

A pesar de los progresos incuestionables que en el ámbito de la documentación histórica ha contemplado en los últimos años la lírica gallegoportuguesa, para el asunto que ahora nos ocupa es justo reconocer que la falta de datos históricos sobre muchos de los juglares que compusieron tales cantigas dificulta la reconstrucción de sus peripecias vitales, como paso previo a la interpretación de los textos. Una solución que se plantea consiste en desplazar el centro de atención de la indagación biográfica al análisis de los medios de producción literaria. Hay que tener en cuenta que al ser la literatura un proceso comunicativo, necesitará que en ella intervengan unos emisores y unos receptores que compartan idénticos código y canal, de modo que sea posible la correcta descodificación del mensaje artístico. En este caso, habrá que partir de una base: la utilización de hagiotopónimos en el marco de un discurso poético tan autorreferencial como el gallegoportugués debe obedecer a un propósito consciente, bien de carácter promocional, bien de aceptación y emulación de un código poético ya consolidado (vid. Beltran, 2002: 14-15).

Esta última opción, que acepta la posibilidad de que, para explicar la confección de un corpus tan amplio como el que estudiamos, haya que pensar en diversas finalidades, no siempre contradictorias, sino a veces complementarias, ayuda a entender, por ejemplo, la presencia entre los cultivadores de las cantigas de santuario de un autor como Afonso Lopez de Baian, miembro de una de las grandes familias de la nobleza portuguesa y que compuso una serie de cantigas en las que menciona a Santa Maria das Leiras; o como Pai Gomez Charinho, trovador procedente de la nobleza gallega, a quien se debe "Ay, San-

${ }^{8}$ Vid. Mussons (1996), quien sugiere la posibilidad de que los cantores de santuario se asocien con el agotamiento de la corte castellana como centro de la lírica gallegoportuguesa tras la muerte de Alfonso X y con la dispersión de los poetas trovadorescos por pequeñas cortes señoriales ubicadas en Galicia. No obstante, dicha posibilidad se contradice con los datos documentales que ligan a los poetas de santuario con los círculos áulicos de Sancho IV. 
tiago, padron sabido" $(114,2)$, pieza que, como sucede con las de Lopez de Baian, no tendría por qué haberse compuesto bajo la demanda de un patrocinador (Correia, 1993: 19-20; Monteagudo, 1998: 106-107).

No obstante, para el presente estudio resulta más interesante atender al presunto componente propagandístico, cuando existe, de este tipo de poemas, ya que supone fijarse asimismo en los posibles círculos patrocinadores y en los intereses que les impulsarían a tal labor de mecenazgo. Esta vía de investigación partiría del contexto histórico en el que se insertaban tanto los templos aludidos en la lírica trovadoresca, como sus poseedores, de tal manera que la información así obtenida se complementaría con la que ofrece el enfoque histórico-biografista.

\section{MARTin CodAX, POETA DE SANTUARIO}

Acaso el más conocido de los poetas de santuario sea Martin Codax, célebre por su cancioneiriño de siete cantigas de amigo, seis de ellas musicadas, que reproducen el Cancioneiro da Biblioteca Nacional de Lisboa (B), el Cancioneiro da Biblioteca Vaticana $(V)$ y la hoja volante conocida como Pergamiño Vindel $(N)$. Este tercer testimonio textual, que ha añadido singularidad a su producción, ha contribuido para que dicho juglar despertase la atención de los estudiosos. Sin embargo, casi nada se sabe acerca de su biografía, lo que nos hurta no pocas claves para el conocimiento de su obra y de las circunstancias en las que la compuso. Debido a este vacío documental, las investigaciones al respecto no han ido mucho más allá de fijar su florecimiento hacia mediados del siglo XIII, derivando este dato de su inclusión en el cancioneiro de xograres galegos ${ }^{9}$.

El misterio que rodea la personalidad de este juglar se extiende incluso a su apellido, caso único no ya en la lírica gallegoportuguesa, sino en la documentación medieval gallega - al menos, bajo la forma Codax -, lo cual ha impedido que se establezca cualquier clase de explicación mínimamente fiable acerca de su procedencia o su filiación. Por tal motivo, la crítica se ha contentado con suponerle una posible naturalidad viguesa ${ }^{10}$, de acuerdo con el método, antes expuesto, que liga geografía literaria y experiencia vital.

\footnotetext{
${ }^{9}$ Así, vid. Brea (1996: 609), que sitúa su florecimiento entre los años 1240 y 1275, en consonancia con las propuestas de Oliveira (1994: 382), quien ubica cronológicamente a Martin Codax a mediados o en el tercer cuarto del siglo XIII, o Tavani (1986: 302), que asimismo opta por mediados del XIII. La posible presencia del juglar en la Reconquista de Andalucía, integrado en el séquito de uno de los magnates de la corte de Fernando III aparece sugerida en Fernández Guiadanes (1998: 27), aunque el único indicio al respecto lo constituye el tema de una de sus cantigas Mandad'ei comigo $(91,4)$, en la que se presenta como inmediata la vuelta del amigo tras servir al rey.

${ }^{10}$ Por ejemplo, Tavani (1986: 302), considera probable la procedencia viguesa del juglar, mientras que Oliveira (2001: 197), precisa que sería "natural de Vigo ou da região circundante".
} 
A este respecto, para dilucidar el origen del desconocido apellido Codax se han propuesto una serie de teorías, unas menos afortunadas que otras, resumibles en tres grupos ${ }^{11}$ : las que lo derivan de un apodo que recibió el autor, bien a causa de una característica corporal, bien de su condición social, bien, más improbable todavía, de términos del léxico marítimo; las que han supuesto que Codax procede de un error de copia de la tradición textual cancioneril; y las que lo consideran un cognomen territorial, cuyo origen debe buscarse, por tanto, en la toponimia, con especial atención a la de la comarca viguesa. El problema de esta última opción es que hasta ahora no se ha encontrado el topónimo a partir del cual podría derivarse su apellido, por lo que Álvarez Blázquez (1998: 20-28) proponía superar el callejón sin salida al que conducía la búsqueda toponímica recurriendo de nuevo a un error gráfico, esta vez entre $-x /-z$ y $-r$, lo que llevaba a centrar la búsqueda en algún hito geográfico que contuviese la raíz codar-, que, no obstante, ha resultado asimismo infructuosa.

Las pesquisas de tipo geográfico, además, han estado condicionadas por las referencias que contiene la producción poética del juglar que tratamos, de ahí que, como acabamos de apuntar, la atención de los estudiosos se haya centrado, preferentemente, en la comarca que rodea a Vigo o, en su defecto, en la costa sudoccidental de Galicia. Sin embargo, la documentación medieval gallega sí ofrece un topónimo susceptible de relacionarse con el apellido Codax, aunque localizado, no en el entorno de la ría de Vigo, sino en las posesiones norteñas del monasterio de Sobrado dos Monxes, en la Terra de Nendos - cuya localización anunciamos en Gutiérrez García (2008)-.

En efecto, el Tumbo primero de este cenobio contiene tres documentos en los que se alude a una población denominada Codais o Quodaix (Loscertales de García de Valdeavellano, 1976: I, 21-23, 139-140 y 160-163). En el primero de ellos (f. 1r-v), un testamento del año 952, se desglosan los bienes que dos vecinos de la localidad de Presares legan a Sobrado, entre ellos unos pomares que se extendían por la citada Codais. En el segundo, del segundo tercio del siglo $\mathrm{X}$, (ff. 42v-43r) Codais y sus pomares aparecen enumerados entre las posesiones de Sobrado "in Nemitos, in commisso de Cinis", esto es, en el coto de Cines, sito a su vez en la ya citada Terra de Nendos, cerca de Betanzos ${ }^{12}$. Finalmente, los ff. 50r-51r del mismo Tumbo Primero reproducen una carta del año 942, en la que se establecen los límites entre la villa de Paredes y Codais, a causa de un pleito que mantenían los vecinos de esta última y los de la pobla-

\footnotetext{
11 Un estado de la cuestión en Fernández Guiadanes (1998: 23-25), en donde se condensa la extensa bibliografía que existe al respecto.

${ }^{12}$ La Terra de Nendos se extendía entre los ríos Mero y Mandeo y comprendía la Mariña dos Condes, con Betanzos y Sada, y la Mariña dos Frades, con Cambre. Vid. Carré Aldao (1936: 140).
} 
ción de Limiñón. De la información que proporciona este conjunto de textos se concluye que Codais se identifica con la actual Cos, parroquia del ayuntamiento de Abegondo, cercana al río Mero y limítrofe con Limiñón y una población, hoy en día desaparecida, llamada Paredes (Rei, 2004: 190-191).

A falta de estudios sistemáticos sobre la toponimia de Abegondo que diluciden la posible etimología del término Codais, la evolución de éste hasta Cos parece explicarse a partir de la pérdida de la consonante sonora intervocálica, a la manera de lo que Moralejo Lasso (1977: 32, n. 26 y 79, n. 47) observa para un topónimo como Colegueses $>$ Coeses o Rei para Adois $>$ Ois $^{13}$. Al respecto, resultan muy interesantes aquellos documentos de finales del último cuarto del siglo XII, en los que se recoge el topónimo Coes, forma evolucionada de Codais. Es lo que sucede, por ejemplo, con el Privilegio rodado de Fernando II, datado en 1177, en el que se fijan los límites del monasterio de Monfero y de las villas de Buriz y Labrada (Colección diplomática, 1901: 453-454); o con la Carta de Pedro III, que expidió en 1185 el citado arzobispo compostelano y que se encuentra depositada en el Archivo Histórico del Reino de Galicia ${ }^{14}$. En este segundo documento se estipulan las compensaciones que había de recibir el monasterio de Cines tras haber sido agraviado por parte de la nobleza local, entre ellas la cesión temporal de Coes y diversas villas al citado cenobio. Como se observa en dichos testimonios, la forma Coes presenta ya la caída de la $-d$ intervocálica, aunque todavía se mantienen las vocales en hiato, antes de su definitiva asimilación.

Por lo que se refiere a la divergencia entre Codais y Codax, habría que considerar la palatalización de las sibilantes finales, que Maia (1997: 461-464) documenta durante la Edad Media tanto al norte como al sur del Miño. Nótese, al respecto, cómo en los textos medievales aducidos por esta autora para ejemplificar tal fenómeno se produce una alternancia entre las formas terminadas en $-s$ y $-x$, que se corresponde exactamente con la que presenta el nombre geográfico que estamos analizando (-aix: Quodaix, frente a -ais/-ays: Codais/Codays). Con las anteriores debería relacionarse la grafía - $a x$, que es la que emplean los cancioneros para la reproducción del apellido Codax, la cual asimismo constituiría un intento de reflejar la pronunciación prepalatal de la sibilante final, teniendo en cuenta que en las grafías de la época se podía marcar la realización de un fonema palatal por medio de una $i$ de refuerzo ${ }^{15}$. Esta última solución

\footnotetext{
${ }^{13}$ Rei (2004: 191) compara la evolución de este topónimo con la de Codais > Cos y sugiere que "os dous nomes semella que teñen algunha relación".

${ }^{14}$ La referencia de dicho documento es AHRG, Colección Vaamonde Lores. Cines, 3.5, n. ${ }^{\circ} 5$. Vid. Lucas Álvarez (1999: 1038), donde, sin embargo, se ofrece una referencia archivística errada.

${ }^{15}$ Vid., por ejemplo, la representación, durante el siglo XII y la primera mitad del XIII en el área lingüística gallegoportuguesa, del fonema africado prepalatal sordo por medio de las grafías chi o chy (Maia, 1997: 468, n. 1).
} 
sugeriría, en fin, la pronunciación paroxítona de Codais, deducible asimismo a partir de su resultado contemporáneo en Cos.

Otra grafía que, como las anteriores, marcaba la sibilante final con valor prepalatal es $-z$ (Maia, 1997: 416). Se empleó en una rúbrica del cancionero $V$ (f. 139rb) para reproducir el apellido del juglar que tratamos bajo la forma Codaz $\mathrm{y}$, no menos interesante, reaparece en dos documentos del monasterio de Oia de 1275 (carp. 1804, doc. 19) y 1278 (carp. 1806, doc. 11), en los que se alude a un tal Fernan Codaz, poseedor de viñas en Sandián (O Rosal), en la comarca del Baixo Miño (Ron Fernández, 2016: 776-777). El indudable interés de este testimonio no explica, sin embargo, el origen del vocablo, por lo que, a falta de un apoyo toponímico para el mismo, deja abiertas las conjeturas que había elaborado la crítica acerca de que en su origen no designase un territorio, sino un apodo o que incluso procediese de un patronímico (vid. Fernández Guiadanes, 1998: 24-25). O, en caso contrario, mantendría abierta la hipótesis del cognomen geográfico y que Codais, a pesar de septentrional, constituyese su referente.

A la vista de los datos expuestos hasta ahora, es evidente que a través de los mismos no resultaría posible la identificación del juglar gallegoportugués, aunque sí se suscitan cuestiones que le afectan de modo más o menos directo. La más inmediata se refiere a la procedencia del apellido en cuestión, ya que la documentación de Sobrado envía a una población situada al otro extremo de Galicia, respecto a la geografía literaria de las cantigas de Martin Codax ${ }^{16}$. Por tanto, toda pretensión de ligar autor y topónimo pasaría, en este caso, por dos posibilidades: o bien ese autor era natural de Cos, de la que tomó el apellido; o bien este le fue transmitido por su familia, que procedía de dicha localidad norteña y que pudo haberse asentado en tierras meridionales cercanas a Vigo.

Centrémonos, en la primera de las posibilidades que se acaban de esbozar; esto es, que el cognomen designase el lugar de nacimiento del individuo que lo lleva. En tal caso, el nombre Martin Codax —o Martin (de) Codax - indicaría la procedencia septentrional del autor, la aldea de Cos, frente a la teoría tradicional que lo hacía natural de Vigo o sus alrededores. Páginas más arriba aludíamos a las dudas que suscitaba la deducción del lugar de nacimiento de un trovador o de un juglar a partir de la geografía literaria que contenía su obra, a la vista de autores que, como Johan Servando, parecían usar el cognomen territorial como "unha especie de emblema do autor" (Monteagudo, 1998: 109) 17; o

\footnotetext{
${ }^{16}$ Paradójicamente, en las cercanías de Cos se encuentra Santa María de Vigo, parroquia del ayuntamiento de Cambre, así como otro lugar llamado Vigo en la parroquia de San Xoán de Callobre. Ambos casos no pasan de la simple anécdota, entre otras razones, porque su ubicación tierra adentro contradice las referencias contenidas en las cantigas de amigo de Martin Codax. Vid. $<$ http://www.xunta.es/toponimia $>$.

${ }^{17}$ Esta hipótesis la había expuesto ya antes Correia (1993: 18) y sobre ella vuelve asimismo Beltran (s. a.: § 13).
} 
como Afonso Lopez de Baian, que por su pertenencia a la alta nobleza no tendría por qué componer a instancias de un patrocinador.

Las limitaciones del aludido sistema de análisis se prolongan cuando, como sucede con no pocos de esos poetas de santuario, incluido Martin Codax, sus datos biográficos y literarios sugieren, tal y como propone Beltran (2002: 7 y s. a.: § 14), su integración en el entorno de la corte de Alfonso X. Este estudioso, por ejemplo, observa las relaciones existentes entre las obras de Martin Codax y Johan Zorro, juglar portugués que frecuentó las cortes de Afonso III y Don Dinis, pero que muy posiblemente residió algún tiempo en la corte castellana. Sería en esta última en la que se habría producido, si lo hubo, el contacto entre ambos autores, pues una composición del mismo Johan Zorro, "Baylemos agora, por Deus, ay velidas" $(83,1)$, sirvió como modelo para "Bailemos nós ja todas tres, ai amigas" $(14,5)$ de Airas Nunez, otro juglar gallego documentado en la corte de Sancho IV ${ }^{18}$.

Con todo, la presencia de un individuo apellidado Codaz, en una comarca del sur de Galicia y en años que coinciden, aproximadamente, con los de la supuesta floración de Martin Codax, abre la posibilidad de que, considerando la identidad Codax/Codaz, la familia del juglar estuviese asentada en aquellas tierras. El Fernan Codaz que mencionan los documentos de Oia, si no hermano (Ron Fernández, 2016: 777) — lo cual es mucho aventurar-, sí que podría ser pariente del juglar gallegoportugués, en la medida en que compartirían apellido; o cuando menos, vendría a indicar el arraigo de ese linaje en un territorio no lejano a Vigo. Lo cual apuntaría a la existencia de alguna clase de vínculo entre Martin Codax y Vigo que, de todas formas, no tendría por qué adecuarse a las pautas que ha supuesto la crítica tradicionalmente - patronazgo, propaganda, promoción de romería, etc., incluso, claro está, nacimiento-.

Este mismo arraigo meridional que demostrarían los documentos de Oia sirve de sostén para la segunda de las hipótesis que planteábamos más arriba: que Codax procediese de una familia septentrional de la hubiese heredado el apellido, con independencia de su lugar de nacimiento. Sin embargo, para su justa ponderación, se precisa un análisis que contemple, tanto la vigencia en la segunda mitad del siglo XIII, de los apellidos de raíz geográfica, como la opción de que dichos cognomina se pudiesen transmitir en el seno de un grupo familiar. Pues bien, a pesar de que el empleo de apellidos geográficos era una opción minoritaria en el sistema antroponímico de la época ${ }^{19}$, su progresivo afian-

18 Tavani (1992: 50) y Beltran (1987: 29-33 y 2002: 6-7), quien, a partir de coincidencias textuales, establece posibles relaciones entre diversos juglares gallegos, entre ellos Martin Codax, y otros trovadores de la época, como Pero Meogo, Martin de Requeixo, Johan de Cangas, Fernand'Esquio o Johan Soarez Coelho, entre otros.

19 Sólo representan el dos por ciento del corpus de Boullón Agrelo (1999: 56-61), si bien tienden al empleo de la microtoponimia. 
zamiento, del que da fe el corpus de autores líricos gallegoportugueses, debe ponerse en relación con los cambios acaecidos en el sistema onomástico medieval y su evolución, a partir sobre todo de mediados del siglo X, desde el sistema de nombres simples al de nombres compuestos. Esta transformación corrió paralela a la reducción del elenco de nombres escogidos y a la elección de nombres cristianos en detrimento de los germánicos. Durante los siglos centrales de la Edad Media, hasta al menos el siglo XIII, el sistema de nombres complejos optó por formar los cognomina a partir del nombre paterno, de forma que, como demuestra la documentación monástica gallega, el uso mayoritario de tal mecanismo denominativo en ese período convierte en anecdóticas otras soluciones, como la que representan los apellidos de tipo profesional, los apodos o los topónimos —vid. Portela y Pallares (1995: 43-47) y González Vázquez y Pérez Rodríguez (1995: 60)-.

Sin embargo, como señala Ventura (1992: 190-191) en su estudio sobre la nobleza portuguesa del siglo XIII, las limitaciones en este segundo sistema condujeron a que a los cognomina formados sobre el nombre del padre se les añadiese otro de tipo geográfico, que tomaba por referencia el lugar de origen del linaje, el cual, con el tiempo, llegó incluso a sustituir al apellido patrilineal. Como muestran los documentos de la época, este apellido territorial podía aparecer precedido o no de la preposición de -así, Mem de Bragança o Mem Bragança, que la propia estudiosa portuguesa pone como ejemplo- Tales cognomina, además, se adecuaban al nivel del linaje que los adoptaba y al de sus posesiones, de forma que los de la gran nobleza eran de tipo regional, mientras que los de la pequeña remitían a una geografía de carácter local. Una circunstancia parecida se observa en lo que afecta a las personas de condición servil o campesina - a pesar de que la evolución del sistema antroponímico presenta ciertas diferencias evolutivas, por ejemplo cronológicas, de acuerdo con los diferentes estratos sociales-, que adoptaban el apellido de su aldea de procedencia (Carzolio, 2002: 165-166 y Mattoso, 1985a: 110-111). Según se desprende de las afirmaciones de Ventura, la frecuencia de tales apellidos no fue uniforme a lo largo del tiempo, al menos en lo que se refiere al reino de Portugal, su ámbito de estudio. A partir de su irrupción a comienzos del siglo XIII, en el reinado de Afonso II (1185-1223) se convertirán en los preferidos de las capas nobiliarias, sin que eso supusiese el abandono de otros mecanismos designativos. No obstante, a mediados de ese mismo siglo, coincidiendo con el reinado de Afonso III o Bolonhês (1247-1279), los apellidos territoriales estaban plenamente asentados.

Tan importante como la consolidación de los cognomina geográficos es la posibilidad de que estos se transmitiesen de padres a hijos. Para ello hay que tener en cuenta las transformaciones de las estructuras familiares que tienen lugar en Europa occidental a partir de los siglos XI y XII y que condujeron de una 
organización de tipo cognaticio, en la que primaban las relaciones horizontales, a otra de naturaleza agnaticia, con predominio de la relación vertical fundamentada en la patrilinealidad (vid. Duby, 1973a y Herlihy, 1983). Esta última se manifiesta por medio de la transmisión de padres a hijos de un solar, garantizado a través de la institución del mayorazgo, de un apellido y de su representación visual en forma de escudo de armas. La nueva concepción linajística, basada en una herencia a la vez material y simbólica, exaltó el concepto de genealogía, lo que explica la composición de nobiliarios, en los que la enumeración de los antepasados reconstruía la memoria del linaje ${ }^{20}$. Por lo que se refiere al norte de Portugal, Mattoso (1980: 383-385; 1985b: I, 205-206) sitúa la transición hacia el nuevo modelo en la segunda mitad del siglo XII —o quizá algo antes entre los infanzones de Entre Douro e Minho-, aunque el cambio hunda sus raíces en el siglo anterior. La mudanza de las estructuras familiares, de todas formas, seguiría un ritmo muy desigual, según un criterio geográfico, y marcando siempre un cierto desfase respecto a la evolución observada en Francia (Mattoso, 1980: 402-415). En esta misma línea, Portela y Pallares (1993a: 269-274) advierten que, en contraste con la cronología que ofrece Duby para el norte de Francia, en Galicia tales cambios en las concepciones familiares se producen con cierto retraso: el nuevo sistema se abre paso a lo largo de una etapa de transición que abarca los siglos XII y XIII y sólo se consolida a finales de esta última centuria y los inicios del $\mathrm{XIV}^{21}$.

La propia lírica gallegoportuguesa ofrece ejemplos de la anterior situación $\mathrm{y}$, lo que ahora nos interesa, de la posibilidad de transmisión de apellidos de padres a hijos. Así sucede, por ejemplo, con Pero Gomes Barroso, cuyos ascendientes procedían de la comarca de Barroso, al sudoeste de Chaves, de la que tomaron el nombre. Con todo, los Barroso no tardaron en fijar su solar más al sur, en las Terras de Basto, por lo que, como muestran los Livros de linhagens, algún integrante de la familia adoptó como cognomen ambos topónimos. Es el

${ }^{20}$ En la península ibérica, el más antiguo conservado es el Livro das linhagens portugués, cuyo Livro velho data de finales del siglo XIII. A lo largo del siglo XIV se compondrían las otras secciones, conocidas como Livro do Deão y Livro do conde dom Pedro. Vid. Mattoso (1993). Resulta interesante comprobar cómo la fecha de composición de esta obra coincide con el proceso de consolidación de la familia agnaticia al norte del Miño, según indicamos a continuación. Vid., para el caso francés, Duby (1973b: 287-298).

21 A este respecto, el análisis del linaje de los Traba que llevan a cabo Portela y Pallares (1993a: 270-271) descubre que esta poderosa familia gallega no comenzó a utilizar el escudo de armas como mecanismo identificador hasta finales del siglo XIII o inicios del XIV. La incorporación del término geográfico de Traba al apellido es, sin embargo, muy anterior, ya que se documenta en la segunda década del siglo XII, aunque todavía no "como nombre colectivo aplicado a un grupo de personas unidas por lazos de parentesco" (Portela y Pallares, 1993b: 281). La conclusión es que sólo en la segunda mitad del siglo XIII se produce la verdadera constitución de un linaje patrilineal (Portela y Pallares, 1993a: 272-273). 
caso de Gomes Viesgas Barroso o de Basto, padre del citado trovador. Es decir, que, aun ignorando en qué lugar exacto nació Pero Gomes, lo más probable es que no lo hiciese en el lugar que indica su apellido, sino en Basto o, en su defecto, en algún otro lugar de Portugal ${ }^{22}$. No menos interesante que el anterior resultan otros ejemplos semejantes, como los Baian y los Tenoiro, que analizó Michäelis de Vasconcelos (1905: 398-407), en los que también se muestra la transmisión del apellido territorial entre los integrantes de una familia. De acuerdo con los datos anteriores, la datación de Martin Codax "em meados ou no terceiro quartel" (Oliveira, 1994: 382) del siglo XIII, abre la posibilidad de que hubiese heredado su apellido en tanto que marca distintiva de su familia. No obstante, tengamos en cuenta que, así como los anteriores ejemplos proceden de la alta nobleza portuguesa y castellana, para la extracción social más humilde del juglar Codax habría que considerar una cronología algo más tardía. Por tal razón, la hipótesis que se acaba de esbozar aconseja no excluir otra vía de indagación.

Además, esta que acabamos de trazar debe supeditarse a la evolución del topónimo sobre el que se construye el apellido que tratamos. A este respecto, debe tenerse en cuenta la ya citada Carta de Pedro III, que se data en 1224, según el cómputo de la era hispánica —es decir, en 1186-; o lo que es lo mismo, unos ochenta años, aproximadamente, antes de la floración de Martin Codax y, por tanto, entre unos sesenta y cincuenta años antes de su nacimiento. La forma Coes, que contiene este testimonio, muestra que ya a finales del siglo XII Codais había caído en desuso, tras haber perdido la consonante sonora intervocálica y haber comenzado el proceso de asimilación de la $a$ final. Esta circunstancia deja abierta la posibilidad de que sus ancestros adoptasen como mecanismo identificativo el citado topónimo, cuando todavía estaba vigente la forma Codais, y que de este modo hubiese llegado al juglar gallegoportugués. Con todo, ante lo improbable de la transmisión patrilineal de dicho apellido desde fecha tan temprana como la que exige el término Codais - aun admitiendo su pervivencia durante el siglo XI, más allá de las fechas indicadas por la documentación de Sobrado-, parece más prudente considerar otra opción que permita salvar la distancia temporal que separa las formas enfrentadas, Cos y Codais.

Quizá el cognomen del juglar que estudiamos, entonces, procediese de la forma arcaica del topónimo Cos, que habría pasado a documentación en romance $-\mathrm{y}$, dentro de esta, a la tradición textual trovadoresca - gracias a que ha-

${ }^{22}$ De hecho, aunque por lógica debió de nacer en Portugal, buena parte de las pruebas documentales lo sitúan en Castilla desde fecha temprana. En 1248, según el Repartimiento de Sevilla, estaba en Andalucía; en 1266 reaparece en el Repartimiento de Murcia, mientras que en 1273, poco antes de su muerte, participó en una misión en Granada, destinada a apaciguar a los nobles sublevados contra Alfonso X (Oliveira, 1994: 416-417 y 2001: 201; Michaëlis de Vasconcelos, 1905: 394-398). 
bría pervivido así en la documentación notarial ${ }^{23}$; y esto, a pesar de que, como muestran los documentos aducidos, al menos desde la segunda mitad del siglo XII, Codais, había dejado paso a otras más evolucionadas. No obstante, podría trazarse una analogía de esta hipotética conservación latinizante y lo sucedido con el topónimo compostelano Pinario, cuya evolución resultó en Piñeiro - doc. Pigneyro - pero que sería relatinizado bajo la forma por la que hoy se conoce (Boullón Agrelo, 2013: 44-45). No perdamos de vista, de todas formas, que las anteriores consideraciones no implican de manera necesaria que Martin Codax hubiese nacido en la villa de Cos; simplemente, que su cognomina, entendido este como procedimiento de identificación trovadoresca, procede de una forma arcaica del topónimo que analizamos.

En este sentido, la opción de que los autores trovadorescos adoptasen sus cognomina como signo de identificación no asociada a su lugar de procedencia abre alguna perspectiva digna de tenerse en cuenta a la hora de estudiar las cantigas de santuario - $-\mathrm{y}$, por extensión, otros aspectos referidos a la contextualización sociohistórica de la lírica gallegoportuguesa- El ejemplo de Pedr'Amigo de Sevilha, junto al tantas veces mencionado Johan Servando - entendiendo su apellido como una referencia al templo dedicado a dicho santo--, muestran que los apellidos geográficos de algunos autores no obedecen a esta única razón ${ }^{24}$. Sea como fuere, la falta de pruebas impide avanzar, en este aspecto, más allá de lo que no sean simples especulaciones teóricas, construidas a base de considerar las diversas posibilidades existentes.

\section{Las Cantigas de Martin Codax. Ambiente DE PRODUCCiÓn E INTERPRE- TACIÓN}

Debido a su efervescencia cultural y su apertura de horizontes artísticos, la corte del rey Sabio, a la que envían los escasos indicios sobre la floración poética de Martín Codax, se configura como el foro idóneo para la eclosión de las cantigas de santuario. Estas, en efecto, se componen al calor del éxito que durante el tercer cuarto del siglo XIII habían alcanzado las cantigas de amigo de tipo tradicional en la corte de Castilla (Beltran, 1987: 32-33), no ajeno, en todo caso, a una tendencia similar observable en otras tradiciones líricas contemporá-

\footnotetext{
${ }^{23}$ Vaya por delante que en la documentación medieval gallega que hemos consultado, sólo hemos encontrado los ejemplos reproducidos en el presente trabajo, que remiten a los fondos del monasterio de Sobrado. Esto no impide suponer, claro está, que otra documentación contemporánea a la floración trovadoresca — bien no conservada, bien inédita— ofrezca más ejemplos de los que han llegado hasta nosotros.

${ }^{24}$ Vid., sobre este autor, Brea (1996: 733), Oliveira (1994: 406-407 y 2001: 200) y Tavani (1986: 311-312).
} 
neas, como la francesa o, incluso, la occitana. Es lógico pensar, entonces, que eran los círculos cortesanos, que gustaban de este tipo de refinadas creaciones popularizantes, los receptores adecuados para tal género de piezas; entre otras razones, porque las grandes cortes, como las regias, resultarían el medio apropiado de difusión de esa pretendida labor propagandística que se les atribuye a dichas cantigas. No supone esto negar la existencia de cortes menores, de carácter comarcal y, acaso, más cercanas a las ermitas gallegas aludidas. Sin ir más lejos, estudios recientes (Monteagudo, 2014; Souto Cabo, 2012; Vieira, 1999) han desvelado el papel central que las cortes nobiliarias gallegas desempeñaron en la emergencia de la lírica trovadoresca gallegoportuguesa. Sin embargo, su localización periférica, el alcance limitado de cualquier reclamación que se efectuase desde ellas o el hecho mismo de que las cantigas de santuario se muestren como un fenómeno complejo, no ceñido a una circunstancia aisla$\mathrm{da}$, son todos ellos factores que contribuyen para que, si existían esas cortes, se mostrasen como altavoces menos capaces de justificar el componente de promoción o reclamación que poseerían tales composiciones ${ }^{25}$. Téngase en cuenta, a este respecto, que esos estudios antes aludidos se centran en el segundo tercio del siglo XIII, y no pocas veces sus conclusiones se refieren a una realidad anterior a la consolidación de las cortes reales como focos difusores del trovadorismo.

Mas, junto al lugar de recepción de dichas cantigas - $-\mathrm{y}$ acaso de producción de muchas de ellas_-, también su interpretación descansa en buena medida en la comprensión del contexto al que se refieren. Es por ello que, para acceder a las claves que permitan interpretar de modo adecuado el cancioneiriño de Martin Codax deberemos tener en cuenta las condiciones que determinaron su composición, pues ellas serán, muy probablemente, las que expliquen los motivos que llevaron a la escritura de esas siete cantigas de amigo. Pues bien, el punto de partida debe centrarse en uno de sus elementos centrales, la mención de la villa de Vigo en seis de las siete piezas que componen el corpus codasiano. ¿Qué razón había para cantar con tanta insistencia una localidad $-\mathrm{o}$, su templo, según precisaremos más adelante - de poca relevancia en la Galicia del siglo XIII? Partiendo de la condición propagandística que se les supone a las cantigas de santuario, habrá que indagar en las vicisitudes que rodean a esta población durante la época trovadoresca, ya que muy posiblemente en ellas se encuentre

${ }^{25}$ Vid., como ejemplo de la postura contraria, sostenida por un sector de la crítica, Monteagudo (1998: 121): "os destinatarios iniciais das cantigas de romaría debían ser persoas moi próximas ós respectivos santuarios". Por su parte, a pesar de que no hace mención a la labor de mecenazgo, Álvarez Blázquez (1980: 82) postula para Vigo una posible "célula poética local", integrada por Martin Codax, Meendinho, Johan de Cangas y Nuno Pérez (sic por Nuno Treez): "Acaso Vigo haya mantenido algo así como una escuela o núcleo poético propio, donde se forjasen estos juglares y aquellos otros de perdida memoria, cuya existencia es presumible". 
la respuesta a su irrupción en la lírica gallegoportuguesa. No obstante, y a falta de pruebas documentales más concluyentes, las propuestas que se aduzcan en este particular han de permanecer, necesariamente, en el terreno de las hipótesis, lo cual no obsta para que se les otorgue la categoría de posibilidad digna de consideración.

En principio, Vigo parece una población de muy limitada importancia en el conjunto de la Galicia de entonces, con escasas probabilidades, por tanto, de albergar un centro de mecenazgo trovadoresco, ya que estaba eclipsada por la capitalidad episcopal de Tui y por los puertos de Baiona y Pontevedra, respaldados ambos por la corona. Su escaso rango se deduce, en fin, de las pocas noticias documentales que a ella se refieren durante la Edad Media y que no remontan a antes del siglo $\mathrm{X}^{26}$. En la época que nos interesa tres grandes instancias de poder - el obispado de Tui, el arzobispado de Santiago y los cistercienses de Melón-, se disputaban el control de la villa y sus alrededores ${ }^{27}$. Las tensiones que surjan en torno a Vigo y su área procederán, muy posiblemente, de los intereses encontrados entre estas instituciones de la nobleza eclesiástica.

Durante el siglo XII buena parte de las tierras de Vigo pertenecían a la sede catedralicia tudense. Esta había recibido diversos dones de realengo, ante el interés de la monarquía leonesa por consolidar las comarcas del Miño, fronterizas con el recién fundado reino de Portugal. De hecho, la amenaza portuguesa se materializó en la ocupación de la tierra de Toroño, que llevó a cabo Afonso I Henriques tras la muerte del monarca castellanoleonés Alfonso VII en 1157, y se prolongaría hasta 1169, cuando Fernando II de León logra restablecer la frontera en la línea del Miño. El cambio de reino no supuso, sin embargo, gran trastorno en la ordenación territorial del sur de Galicia. Antes al contrario, Afonso Henriques no sólo confirmó las posesiones anteriores de los tres grandes poderes ya mencionados (Fernández Rodríguez, 2004: 107; Portela Silva, 1976: 248-249), sino que, por ejemplo, reafirmó los dominios del obispo de Tui confirmándole el realengo de Bembrive y el derecho a cinco barcos fondeados en el puerto de Vigo.

Entre 1170 y 1180 Fernando II de León, una vez recuperada la tierra de Toroño, concede la iglesia de Santa María de Vigo al obispo tudense

\footnotetext{
${ }^{26}$ En dicho documento, de 915, se menciona Bembrive, una parroquia del Vigo actual, pero que por aquel entonces era una aldea integrada en el coto de Turonio (Sánchez Bargiela, 1999: 91). El nombre de Vigo no aparece hasta 1097 (Melón, Car. 1437, n. ${ }^{\circ}$ 3), con ocasión de un conflicto de límites entre esta población y la contigua de Canadelo. Vid. Álvarez Blázquez (1980: 6566), Fernández Rodríguez (2004: 72) o Sánchez Bargiela (1999: 104).

${ }^{27}$ Tampoco hay que perder de vista la presencia de la nobleza de origen laico, que asimismo disfrutaba de posesiones nada despreciables en la comarca. La gran finca de Condomiñas, por ejemplo, pertenecía a la condesa Fruila Fernández, hasta que esta la donó al monasterio de Melón en 1158. Vid. Álvarez Blázquez (1960: 7 y 181), Santiago y Gómez (2005 [1895]: 198-199), Fernández Rodríguez (2004: 105) y Sánchez Bargiela (1999: 150), en donde se ofrece una enumeración de las posesiones de nobles laicos en la comarca de Vigo.
} 
(Fernández Rodríguez, 2004: 116). Pero, al tiempo, fomenta la instalación del monasterio cisterciense de Santa María de Melón, presente en la comarca desde 1158 , gracias a que una donación particular le había otorgado la propiedad de Condomiñas, finca de grandes proporciones al sur del monte del Castro (Melón, Car. 1437, n. $^{\circ} 10$ y 17). Fernando II reforzará su presencia en la ría con posesiones en los alrededores de Redondela y, en 1176, con el realengo de Vigo.

Hasta 1234, los sucesivos reyes de León no alteran el reparto territorial de la zona. Pero en ese año los monjes de Melón inician un pleito contra el arzobispo de Santiago, al que acusan de haberles usurpado los derechos sobre Vigo (Álvarez Blázquez, 1980: 94-95; Santiago y Gómez, 2005 [1895]: 198-201; Sánchez Bargiela, 1999: 93-94)28. Álvarez Blázquez (1960: 395 y 1980: 94-95), que sigue en este particular a Santiago y Gómez, supone que al prelado compostelano le asistían derechos anteriores a la concesión de 1165, que este autor remonta al tiempo de Gelmírez y a la obligación de este arzobispo de mantener naves de guerra para la protección del litoral. Sánchez Bargiela, en cambio, se muestra más cauto al respecto, limitándose a constatar que, debido a la escasez documental, resulta imposible de concretar en qué derecho se basaba la apropiación por parte de Compostela. Pero, al mismo tiempo, pone en relación esta actuación con la expansión que por esos mismos años lleva a cabo el arzobispado por tierras de la ría de Vigo, en la que consolidó su presencia con adquisiciones en $\mathrm{O}$ Morrazo, Redondela, Cedeira, Teis o Valadares (Sánchez Bargiela, 1999: 94) ${ }^{29}$. Este proceso de asentamiento en la más meridional de las rías gallegas habría comenzado en 1184, cuando el arzobispo Pedro Suárez de Deza obtuvo de Fernando II la concesión del castillo de Darbo, en Cangas, cuya jurisdicción abarcaba la mayor parte de la península del Morrazo, y, algo posterior, ya bajo el reinado de Alfonso IX, la del castillo de San Paio de Lodo (actual Pontesampaio), en el fondo de la ría, cuyo emplazamiento tenía gran valor estratégico por estar en la ruta que unía Portugal con Santiago (González Vázquez, 1996: 50-51; Barreiro Somoza, 1987: 387 y 390 $)^{30}$.

\footnotetext{
${ }^{28}$ La reclamación se centra, en varias propiedades de la ría, incluyendo Condomiñas, posesiones en Teis y la que se denomina como "uilla de Vico". Esta, a su vez, se extendería "inter Cunduminas ex una parte et Teys ex altera" (Melón, Car. 1441, n. ${ }^{\circ}$ 16). Vid., además, la transcripción del documento en Cambón Suárez (1957: IV, 269).

${ }^{29}$ González Vázquez (1996: 50), añade a estas otras propiedades en Saiáns y Matamá, todas ellas en los alrededores de Vigo.

${ }^{30} \mathrm{Sin}$ embargo, la adquisición de propiedades por parte de la mitra compostelana en la ría de Vigo es sólo un episodio más en su proceso de expansión por el suroeste de Galicia. Este se documenta ya en tiempos del antecesor de Pedro Suárez, el arzobispo Pedro Gudestéiz, quien unos años antes había conseguido el castillo de Cedofeita, en las inmediaciones de Pontevedra, y otras jurisdicciones en esa comarca. Pedro Suárez completó la labor, consiguiendo donaciones reales en tierras del Salnés, la desembocadura del Lérez y el burgo de Pontevedra, así como la parroquia de San Julián de Encoirados y la cercana aldea de Marín, con su puerto (Barreiro Somoza, 1987: 384-387).
} 
El proceso al que se acaba de aludir se inscribiría en la demanda, por parte de Compostela, de las fértiles tierras del sur, a causa, por un lado, de su especialización en el cultivo vitivinícola y cerealístico, junto a los rendimientos que ofrecían sus recursos pesqueros; pero por otro, como acaba de insinuarse al hablar de San Paio de Lodo, debido al incipiente desarrollo comercial que protagonizaban las Rías Baixas. Por lo que se refiere al interés compostelano sobre Vigo, habría que tener presente otro factor, complementario del anterior, como es el progresivo control que la mitra de Santiago fue estableciendo sobre los puertos cercanos a su jurisdicción, de realengo y muchos de ellos de reciente fundación, con vistas a evitar la competencia que pudiesen representar para el puerto de Padrón. Por este motivo, durante la segunda mitad del siglo XII y todo el siglo XIII, el arzobispado procuró obtener de la corona los derechos sobre estos burgos, que mostraban una naciente pujanza, hasta que, a finales del XIII e inicios del XIV, la corona cesó el flujo de estas donaciones e incluso, como sucedió en 1309, con Fernando IV, decretó la anulación de tales cesiones (González Vázquez, 1996: 108-113). En esta fase de reflujo habría que insertar, asimismo, la actitud de Alfonso X hacia la mitra compostelana, que culminó en su enfrentamiento con el sucesor de Juan Arias, el arzobispo Gonzalo Gómez, a partir de 1273. El monarca castellano, además de organizar una expedición armada contra Compostela, intentó la desposesión de los burgos portuarios de realengo cedidos a Santiago. López Ferreiro (1902: V, 242) ${ }^{31}$ menciona, entre estos, a "La Coruña, Pontevedra, Padrón, Noya, etc.", pero es posible que haya que incluir también a Vigo, si tenemos en cuenta su condición de villa arzobispal desde unos cincuenta años antes.

Sea como fuere, y al margen de estas contingencias, el pleito entre Santiago y Melón debió de prolongarse en el tiempo y, aunque se desconoce la sentencia, lo cierto es que Santiago quedó en adelante como dueño del coto de Vigo, que englobaba las iglesias de Santa María y de Santiago. La primera se ubicaba sobre el promontorio de A Laxe, en el que acabaría por convertirse en el centro de la villa, y, por tanto, a escasos metros del mar. La segunda, y el barrio que la rodeaba, muestran una localización más imprecisa. De acuerdo con Álvarez Blázquez (1980: 74), ambos se erguían en la línea costera que formaban la playa y el arrabal del Areal, junto al camino que conducía a Pontevedra; y su solar, que este estudioso ubica a la altura de la actual calle Pontevedra, coincidiría con el que, a partir de 1550, ocupará un hospital de la Orden Tercera. Por aquel entonces la iglesia de Santiago habría pasado al camino de la Areosa, tie-

${ }^{31}$ Más adelante añade este autor: "Entretanto D. Alfonso había consumado su obra. Se apoderó de la pertiguería de Santiago y de los castillos de la Rocha, de Jallas, de Oeste, de Lobería, de Sampayo, de Cotobad, de Daravo, de Alcobre, de la Lanzada, de las Encorvas, de Aguiar, de Teis y de las torres de Santiago y de Padrón” (López Ferreiro, 1902: V, 244). 
rra adentro sobre la falda norte del Castro. Sánchez Bargiela (1999: 90) ${ }^{32}$, por contra, sitúa la iglesia de Santiago durante la Edad Media, en ese emplazamiento a mitad de subida del monte del Castro, "nun lugar chamado antigamente «A Ladeira»", que ocuparía los terrenos de la actual calle Venezuela. Este autor postula la ocupación de ese espacio por parte de un núcleo poblacional que está documentado desde el siglo XI y que, como revelan ciertos hallazgos arqueológicos, acaso remontase al período altomedieval.

No obstante, la adscripción de Vigo a la mitra de Santiago no supuso el fin de la presencia de la sede tudense y, sobre todo, de los monjes de Melón. Así, por ejemplo, se sabe que en el siglo XV estos últimos explotaban un puerto en el lugar llamado Chano dos Pelames, que ofrecía mejores instalaciones y condiciones de abrigo que el que pertenecía al arzobispo compostelano. Melón también disfrutaba de diversas propiedades en Vigo y sus alrededores - como Sárdoma o Teis - incluyendo la ya citada granja de Condomiñas, así como tierras de labor y un celeiro en Santa Uxía (actual Santa Marta), sobre la ribera del Berbés ${ }^{33}$. Con ser menor, el poder del obispado de Tui en la comarca viguesa era también considerable. Desde mediados del siglo XII poseía, entre otros bienes, los realengos de Bembrive y de Santa María de Vigo y, ya en los siglos XIV y XV, conseguirá el coto de Coia, el señorío de Coruxo y fundará la villa de Bouzas, con la que pretendía rivalizar con el puerto arzobispal de Vigo. A todo esto, la sede tudense añadía la pretensión de hacerse con los derechos sobre las iglesias viguesas en manos de particulares. Así sucede, por ejemplo, con la de Santiago de Vigo, que consigue ca. 1200, o la de San Salvador de Teis, donada al obispo D. Lucas en 1245 (Sánchez Bargiela, 1999: 139-143; Álvarez Blázquez, 1960: 505).

Especialmente importante se revela este último detalle, pues recordemos que el templo constituye uno de los elementos fundamentales, desde el punto de vista conceptual, sobre los que se asienta la poética de las cantigas de santuario. Por tal razón, habría que considerar las tensiones que podrían haber surgido durante el proceso, al que acabamos de aludir, de transferencia, entre propietarios laicos y eclesiásticos, de las iglesias viguesas. A este respecto, la propiedad de una iglesia implicaba los derechos de patronato y presentación,

\footnotetext{
${ }^{32}$ Como se observa, la cercanía al mar del primero de los dos templos vigueses, dedicado a Santa María, propiciaría su identificación con la "igreja de Vigo" que aparece en el cancioneiriño de Martin Codax. Ahora bien, el valor de este género de reconstrucciones arqueológicas pierde valor debido a dos motivos. En primer lugar, el empleo del lenguaje codificado de las cantigas de amigo por parte de Martin Codax exige que entre sus topoi se incluyan las referencias al mar, ya que sus piezas se ambientan en una localidad marítima. En segundo lugar, como se indica a continuación, el papel del templo - cualquiera de ellos - es secundario en las siete cantigas sobre Vigo, frente al que se le concede a la localidad en su conjunto.

33 Sánchez Bargiela (1999: 121 y 135-139), quien enumera estas propiedades.
} 
además de los bienes territoriales que dependían de ella, así como la percepción de las rentas derivadas de estos derechos (Portela Silva, 1976: 218-219). Correia (1993: 14-17), por su parte, recuerda que los templos se sustentaban con los fondos que obtenían de sus devotos y que los destinatarios de esas rentas eran sus propietarios - fuesen laicos, eclesiásticos o ambos a la vez, en régimen de propiedad compartida-, aspecto este que resulta esencial para establecer una relación con la lírica trovadoresca y un posible sistema de propaganda y mecenazgo.

El desplazamiento de los laicos, por parte de la Iglesia, en la posesión de los templos tiene lugar a lo largo de los siglos xii y xiii y bajo el impulso de la reforma gregoriana. La cronología de este proceso en tierras del obispado de Tui, que ofrece Portela Silva (1976: 216), muestra que el mayor número de donaciones, por parte de propietarios laicos, se produce en los cien años transcurridos entre las décadas de 1120-1140 y 1220-1240, observándose un ligero repunte en los últimos veinte años del siglo $\mathrm{XIII}^{34}$. Quiere esto decir que el florecimiento de las cantigas de santuario coincide con la fase final de esta transferencia en la propiedad de los templos, lo que invita a considerar la hipótesis de una posible relación entre los acontecimientos histórico y literario. No obstante, y al margen de las posibles conclusiones que puedan extraerse de estos datos en lo que se refiere al conjunto de la poesía de santuario, si nos ceñimos a las cantigas codasianas, hemos de tener presente las circunstancias concretas que afectan a una de las dos iglesias que se identifican con Vigo, Santa María o Santiago. Esto implica que dejamos fuera de nuestras consideraciones otras, como Santiago de Bembrive, San Salvador de Teis o San Andrés de Comesaña, que, si bien cercanas, se levantaban en parroquias que se identificaban con un topónimo propio $\mathrm{y}$, por lo mismo, gozaban de suficiente entidad como núcleo poblacional independiente. Ahora bien, ambos templos vigueses estaban vinculados al obispado de Tui desde, al menos, la primera mitad del siglo XII, sin que, durante el período de floración trovadoresca, se tengan datos acerca de conflictos por la posesión de las iglesias de Santa María o Santiago. La noticia más cercana a la época que nos interesa data de 1183 y se trata de la concordia que sobre los derechos del segundo de estos templos firman el obispo D. Beltrán y Pedro Pérez, el particular que los disfrutaba.

Por otro lado, al hablar de las composiciones de Martin Codax, hay que hacer alguna salvedad, ya que dos de ellas están ambientadas, respectivamente,

\footnotetext{
${ }^{34}$ Las cifras que ofrece este autor son las siguientes: entre 1120-1140, once iglesias donadas; entre 1140-1160, cincuenta iglesias; entre 1160-1180, dieciocho; entre 1180-1200, veinte; entre 1200-1220, doce; entre 1220-1224, veintidós. A partir de esta fecha, se observa una disminución en el ritmo de donaciones: entre 1240-1260 se reducen a siete y entre 1260-1280, a seis, para remontar a diecisiete entre $1280-1300$.
} 
en la igreja y en el sagrado de Vigo, pero otras cuatro se contentan con mencionar el nombre de la población ${ }^{35}$. Es decir, esta última aparece en seis de sus piezas $^{36}$, frente a dos referencias de tipo sacro. Dicho con otras palabras, al margen de la indudable cohesión textual del cancioneiriño de Martin Codax, que permitiría la interpretación implícita de elementos de algunas piezas a partir de otros que se encuentran presentes en otras composiciones ${ }^{37}$, parece no menos evidente que en ellas el aspecto religioso se muestra muy secundario, apenas un motivo más entre la red de referencias poéticas de la cantiga de amigo. Visto lo anterior, no queda por menos que cuestionar la pertinencia de seguir asociando las presentes cantigas a cuestiones relacionadas con asuntos del culto y de la propaganda devocional o, incluso, con la gestión y propiedad de los santuarios vigueses.

Este último pormenor obliga a considerar otras posibles explicaciones, en las que, por encima de los asuntos religiosos, pesen más los intereses profanos derivados de la posesión de la villa. De los datos que nos ofrece la documentación contemporánea, el más importante parece ser el litigio que, en 1234, surge entre Santiago y Melón por los derechos sobre el coto vigués. Estos suponían el ejercicio de la justicia en el territorio así delimitado y la percepción de las rentas producidas en el ejercicio de tales derechos (Portela Silva, 1981: 123124). Téngase en cuenta que, si la floración de Martin Codax se produce entre mediados y el tercer cuarto del siglo XIII, estaríamos hablando de no muchos años después del comienzo del citado pleito, cuando, en vista de la incierta resolución que tuvo, es probable que permaneciese todavía abierto.

Para ahondar en esta interpretación de las composiciones que analizamos, ajena a la tradicional que vincula las cantigas de santuario con la gestión o la promoción de los templos que en ella se mencionan, habría que cuestionarse, en fin, el lugar que ocupa el cancioneiriño de Martin Codax en el conjunto de la poesía de

35 Esta ausencia lleva a Brea (1999: 389) a incluir tales composiciones en el elenco de cantigas complementarias a las cantigas de santuario, "porque, si no las ponemos directamente en relación con las otras del mismo autor, sería difícil deducir que Vigo hace referencia a un santuario". Vid., también, Correia (1993: 18-20).

${ }^{36}$ Otros ejemplos hay de cantigas de santuario en los que aparece el topónimo, pero no el templo y la advocación a la que estaba dedicado. Tal sucede en las cuatro cantigas de santuario de Bernal de Bonaval (22,7, 22,13, 22,16, 22,19); en cuatro de Johan de Requeixo (67,1, 67,3, $67,4,67,5)$, sobre un total de cinco, mientras que la quinta $(67,2)$ alude a la ermita de Faro; o en dos de las seis piezas de Martin de Padrozelos $(95,1,95,7)$. Las respectivas producciones poéticas, claro está, deben leerse como otros tantos macrotextos, cuyo verdadero significado sólo se obtiene a través de la lectura conjunta de todas las cantigas de un mismo autor, de ahí la existencia de elementos sobreentendidos como el nombre del templo y de su advocación.

37 Tal es, por ejemplo, la opinión de Tavani, para quien las cantigas de amigo de Martin Codax "formam, na minha opinião, um único "texto" e, portanto, não devem ser lidas separadamente" (Tavani, 1998: 51). 
santuario, sobre todo en lo que afecta al topónimo que lo cohesiona. Acabamos de ver que este destaca por el papel secundario que en él desempeña el componente sacro, en comparación con el aspecto profano, frente a las reiteradas menciones a la localidad en la que se asienta este templo. Ahora bien, esta última no puede por menos que ponerse en relación con una de las características de las cantigas de santuario, cual es la de que los templos cantados en estas son ermitas situadas en un emplazamiento rural, lejos de los centros de población.

Líneas más arriba indicábamos que Vigo permanece, durante esta época, eclipsada por otros núcleos de población más pujantes en el sur de Galicia. En esta comarca, el despegue protourbano de la Edad Media central lo protagonizaban otras poblaciones; especialmente dos, Pontevedra y la sede obispal de Tui, a las que se les podrían añadir los puertos de Baiona, A Guarda y Redondela, junto al enclave fronterizo de Salvaterra. En esta línea se manifiesta Sánchez Bargiela (1999: 107), para quien Vigo presentaría las características de un agrupamiento de tipo aldeano, es decir, un núcleo de pocas casas agrupadas sin que formasen entre ellas calles con un trazado definido. Por lo demás, Portela Silva (1976: 77-83) define en términos semejantes las villae — vocablo con el que se designa a Vigo- mencionadas en la documentación de los siglos XII y XIII, añadiendo que constituían núcleos de población que configuraban un hábitat agrupado, en el que "las casas se sitúan en función de los caminos". Frente a las ciudades, además, estas villas carecían de murallas, la cuales distinguían a aquellas respecto a los asentamientos rurales.

Sin embargo, el carácter rural del Vigo del siglo XIII merece, cuando menos, alguna matización, ya que algunos datos permiten pensar en un crecimiento demográfico sostenido a lo largo de esos años. Por ejemplo, llama la atención la existencia de dos iglesias, Santiago y Santa María, documentadas al menos desde 1136, lo que revela, según Santiago y Gómez (2005 [1895]: 161), "que Vigo era un lugar importante cuando contaba con dos parroquias". Tal afirmación parte de la suposición de que ambos templos aglutinaban, de manera simultánea, sendos núcleos habitados, aspecto este que pone en duda Sánchez Bargiela (1999: 129), quien sostiene que el poblamiento de uno de estos enclaves suponía el declive poblacional del otro, en un claro síntoma de debilidad demográfica. No obstante, este mismo autor reconoce que la promoción, durante esta época, de Santa María a parroquia confirmaría su capacidad de atraer y fijar habitantes; y en la misma dirección de aumento demográfico sostenido apuntaría la disputa entre los vecinos de Vigo y Canadelo por los límites entre ambos asentamientos, que se refleja en el documento, ya mencionado, de $1097^{38}$.

38 “... o feito de que no ano 1097 os homes de Vigo e de Canadelo disputaran os limites das súas aldeas... pódese interpretar coma um indicio dun crecemento demográfico que leva a disputar unha terra, posiblemente inda inculta, pero necesaria para amplia-la base productiva" (Sánchez Bargiela, 1999: 104). 
Otro detalle a tener en cuenta sería el relativo a la posible existencia de un sistema defensivo, que indicase una cierta concentración poblacional, aun de escaso relieve. En el documento por el que Fernando II donaba el realengo de Vigo al monasterio de Melón (1176), se mencionan, entre las posesiones que se otorgaron, "regalendum habeatis cum pascuis, cum montibus, cum fortibus..." (Cambón Suárez, 1957: III, n. 44). Álvarez Blázquez (1960: 7 y 1980: 89) deduce de este último término que la localidad poseía algún tipo de muros de defensa, que, sin embargo, puede que no alcanzasen la categoría de verdaderas murallas, que distinguían a los asentamientos urbanos (Sánchez Bargiela, 1999: 128). Ahora bien, tales muros estarían indicando, por lo pronto, un poblamiento concentrado con la suficiente entidad como para organizar un sistema de protección, por muy rudimentario que este fuese y por muy limitadas que fuesen las proporciones del núcleo defendido. Y ese núcleo sería capaz, también, de proporcionar naves para la conquista de $\operatorname{Sevilla}^{39}$ o, como indica la cesión de Afonso I Henriques al obispo de Tui (1169), de que acogiese cinco embarcaciones fondeadas en su puerto, con sus tripulaciones (Álvarez Blázquez, 1960: 129 y 1980: 90; Torres Luna 1986: 314; Santiago y Gómez, 2005 [1895]: 107 y 162), incluso aunque se tratase de simples naves dedicadas a la pesca de bajura en la ría (Sánchez Bargiela, 1999: 122) y de que su puerto, a causa de la política de bloqueo del arzobispado compostelano, careciese de relevancia.

En conclusión, ¿respondía la igreja de Vigo al perfil de ambientación rural que era característica de la poesía de santuario? Aun sin ubicarse en un medio urbano y considerando a Vigo una villa o aldea, parece que tampoco responde al perfil de muchas otras ermitas del corpus gallegoportugués, situadas en emplazamientos más remotos y menos habitados - algunas, hasta el punto de presentar hoy en día una ubicación imprecisa- Bien es cierto que este motivo, el de la alusión a iglesias rurales, no se atiene a una regla fija y actúa como simple tendencia sujeta a variaciones. Sin embargo, esta diversidad en la tipología de los santuarios reflejaría una pluralidad semejante en lo que afecta a los propósitos y los motivos que se esconden tras su mención en la lírica trovadoresca. Valgan a este respecto los ejemplos, de Airas Nunes o Pai Gomez Charinho, sobre los que ya hemos hablado, cuyas alusiones a Santiago, ligadas al viaje a Compostela de Sancho IV, revisten un carácter más político que devocional, incluyendo bajo este término la propaganda del templo, del santo que sirve de advocación o de la romería que se pudiese celebrar en su honor.

Como conclusión, las consideraciones anteriores invitan a replantear las condiciones de producción y recepción de las cantigas de santuario, empezando

\footnotetext{
${ }^{39}$ Más que en la presencia de una flota, habría que pensar en que dichos barcos fueron construidos en astilleros de la ría. Esta capacidad era muy común en los puertos de la Galicia medieval (Ferreira Priegue, 1988: 288), pero refuerza al menos la idea de Vigo como pequeña localidad costera.
} 
por descartar la denominación de cantigas de romería, pues la variedad de situaciones que se esbozan al respecto desborda el estrecho marco que sugiere esa etiqueta. Muchas de estas cantigas estarían ligadas a algún tipo de promoción o reclamación, pero no se explican, necesariamente, por una labor de propaganda para atraer devotos, como había sugerido la crítica. Por ejemplo, un factor de análisis al que habría que prestar más atención es el del uso de los hagiotopónimos en su función poética, como marcas de estilo; es decir, atendiendo a lo que esos nombres de lugar tienen de geografía literaria, de marca textual que se integra en un sistema de rasgos estilísticos, y no, por fuerza, de documento de la experiencia vital del autor. La mención de tales topónimos funcionaría, entonces, como un elemento caracterizador, que identificaría las composiciones que componen un corpus poético y al autor de dicho corpus en su relación con el templo, pero también en su condición de poeta. Piénsese, a este respecto, en la importancia que reviste el componente autorial en un corpus, como el gallegoportugués —o, también, el occitano-, en el que la anonimia es poco menos que anecdótica. De modo paralelo, el afán por significarse en el seno de esa tradición lírica, dotada de un alto grado de isomorfismo, conduciría al empleo de elementos invariantes distintivos que operarían en diversos niveles, uno de los cuales podrían ser los hagiotopónimos de las cantigas de santuario. Se entendería así, por ejemplo, que un aristócrata como Lopez de Baian aludiese a Santa Maria das Leiras, pues mencionando sus posesiones singularizaba sus cantigas y se reafirmaba él mismo como su señor y como poeta.

Abundando en las observaciones vertidas por Beltran (1987 y 2002), que, según veíamos más arriba (vid. supra, p. 344), extendía esas marcas a otros elementos de las cantigas de amigo tenidos por tradicionales, Weiss (1997: 234236) observa que esa misma función correspondería a la utilización recurrente de ciertas fórmulas fraseológicas en las cantigas de amor. Aunque sus ejemplos se centran en la producción de Vasco Praga de Sandim, extiende dicho rasgo a otros trovadores, como Martin Moxa o Vasco Perez Pardal, y enlazaría con análisis semejantes que Zumthor (1972) realizó en la chanson de la lírica d'oül y Ziegler (1975) en los minnesänger. Pero con la potenciación de la dimensión autorial también se relacionarían otros recursos que actúan a nivel macrotextual, como la secuenciación de cantigas y los diversos modos de conseguir su cohesión textual: esquemas métricos, figuras del ornato, motivos, léxico o, claro está, los hagiotopónimos. Lejos de restringirse a un grupo concreto de poemas, la secuenciación muestra una difusión amplia en el trovadorismo peninsular, con unos límites difíciles de fijar. Pero más interesante aún, se vincularía con esa misma tendencia a construir las producciones poéticas en torno a la figura del autor, al modo de lo que ejemplifican las Cantigas de Santa María o el Libro de buen Amor o, fuera de la Península, el Voir dit de Guillaume de Machaut o el Canzoniere de Petrarca (Weiss, 1988). 
Esta función poética, con todo, no contradice la dimensión pragmática de las cantigas estudiadas, de forma que sirviesen de cauce a algún tipo de reclamación. El estudio del contexto al que enviaría ese componente pragmático de las cantigas de Martin Codax apunta a diversos supuestos que podrían explicar su composición. Y estos, más que referirse a la llamada a una romería, parecen apuntar a conflictos suscitados en Vigo y su comarca en esa época. De los que hemos considerado, el más sugerente sería el litigio que el monasterio de Melón abrió en 1234 contra el arzobispado de Santiago por la usurpación del señorío de Vigo y que se encuadraría en la creciente presión que la mitra compostelana ejercía sobre la ría viguesa desde finales del siglo XII.

Si las cantigas codasianas se compusieron al calor de los enfrentamientos generados por ese proceso de expansión, parece lógico pensar que surgiesen en contacto directo con el origen del problema y que sus agentes - patrocinador, autor - estuviesen ligados de algún modo a Vigo. Sin embargo, para que fuesen eficaces en su tarea reivindicativa, deberían difundirse más allá del ámbito comarcal en el que habrían surgido, lo que habilitaría a la corte real como centro de recepción más probable. Esta apertura de horizontes debería hacerse extensiva a la concepción misma de las cantigas de santuario, las cuales han de entenderse como un fenómeno literario no local, sino peninsular. Y tal apertura afectaría, incluso, al arraigo de los autores que las cultivan, a los que hay que suponer menos sometidos a la esclavitud de la inmediatez física a los templos que cantan y sujetos a una mayor movilidad espacial. El caso de Martin Codax, que apunta a la vez a algún tipo de ligazón con el sur de Galicia y a una posible procedencia familiar norteña, sirve de ejemplo para insertar a estos poetas de santuario en un ámbito espacial más acorde con la amplitud y la apertura geográfica y cultural del trovadorismo ibérico.

\section{APÉNDICE DOCUMENTAL}

Hoc est prima series testamenti Sancti Iacobi de Superado quam fecerunt Hermegildus et Paterna

Item uilla quod uocitant Roziata ad integro per suos terminos antiquos, in ualle Nemitos uilla [Melangus] que dicitur [+6] cum domos uel omnibus intrinsecis suis ad integro, ipsa uilla cum omnibus prestationibus suis. In uilla Codais pumares quos comparauimus de Uistella seu et uillare Requilani ad integro secundum quomodo illum obtinuit genitore nostra dom[na] Argilo cum pumares et exitus suos, uel quantum nos ibidem obtinuimus. Omnes has uillas concedimus ecclesie sancte cum domos, edificiis, com omnia genera pomorum cum pratis, pascuis, padulibus, exitus montium, aquis aquarum cum ductibus suis, uel omnia quicquid apud omnes pertinet in ipsas supradictas uillas... (Loscertales de García de Valdeavellano, 1976: I, 21-23). 
Hi sunt termini de commisso de Superaddo confirmati a Serenissimis Principibus Ordonio Rege et Ranemiro Rege et matre eius Tharasia Regina

Isti sunt termini de commisso de Presares quod est integro de Superato... in Nemitos, in commisso de Cinis, ecclesia de Santa Maria de Colliargundo cum duas uillas, ecclesia de Ioanzo cum duas uillas, ecclesia de Presedo cum adiacentiis, uilla Melancos, et uilla que dicunt Martini, Quodaix cum suos pumares, casale de Anderiz; Varcena ad illa porta de Cinis et Paredes, villare de Spelunca, Karedugma cum ecclesia Sancta Eolalia de Spelunca, uillare Riquilani, uillare de domno Suario, Pontelias, ecclesia de Calambre cum adiacentiis suis, uilla Odroci, uilla Prauio, uilla Cicebre, uilla de Noz, uilla de Oix cum adiacenciis suis. In terra de Faro, Sancta Eolalia de Cariolo et ecclesia Sancta Maria, et uilla de Orrio, et ecclesia de Ozia, uilla Basobre, uilla de Azobre (Ibíd.: 139-140).

\section{Karta de uillari de Paredes, quod iacet inter Codays et Lemenionem}

\section{CXXVIII}

In nomine Domini. Notum manet omnibus episcopis et comitibus et militibus quibusque ad serenissimum gloriosum principem nostrum Adefonsum iudicandi potestas concessa est, cuius se epistole textum subsequitur quamuis de duarum partium intentio uertatur de diuersis asertionibus porrigantur, si tamen omnis controuersio legitime fine concluditur, cum expeculatione iudicium gratis moderanime superata censetur. Igitur ex presenti tempore domni Adefonsi principis, orta fuit intentio inter Sesnandum filium Gondesindi et homines de Lemenioni, neptos Lemeni, cuius uocem Sesnandus asseret contra neptos Endulfi et Astruildi. Id sunt, Ueremudus, Baltarius, Tructesindus, Egica, Fofu, Engladio, Fridiuerto, habitantes in Codais. (...) Et dixerunt omnes illi una pariter, quia una uilla est Codays et ipsum uillarem de Parietes. Et uenerunt omnes omnes illi una pariter ad ipsum episcopum et ad ipsos comites et iudices, ut preuidissent ueritatem inter Quodais et ipsum uillarem de Paredes. Et uenerunt ibidem ad ipsas uillas per sugessionem de Sesnando et de ipsos heredes, scilicet Ueremundus, Baltarius, uel de illorum heredes, id est, domno Rodesindo episcopo, Pelagio, Segeredi, Alumi, Erus, Galendus, item Erus, Odoarius Romariz, Cisila abba, Gauinus, Gefera, et alii multi preuisores, que diuiserunt inter Codays et ipsum uillarem de Paredes. Inuenerunt archam in ripam de Mero, ubi dicent ad Canarium et de Coria in directo de ipsa archa in directo Sancto Stephano, et alia archa principalia iuxta uiam de Codais, et inde ad fontem Iusteli, et de Coria ad illas cercarias que bouca que dicent Tructesindi. Et tercia archa in quoto super uarzinam de Bouea et de Coria in ipsa uarzina de Bouea. Et quarta archa in ripa de ipso rio de Bouea. Et quinta archa, que de Coria inter Melangos et Parietes. Et sexta archa in Bauza, que dicent Cerquitum, qui diuidet inter Trius et Parietes. Et alias archas et de Corias que diuident inter Lemenioni et ipsas Parietes et Caliobre. Et concludent per fontem bonam in directo usque ad ipsam archam quem primiter inceperunt inter Codais et Parietes. Et preuiderunt ipse episcopo et ipsi comites, abbates et preuisores tuti quia ueritas est de isto Sesnando et de suos auctores. Et ordinauerunt ipse episcopo et illi iudices ad illum sagionem Fofum, ut asignaret ipso uillare de Parietes ab integro per suos terminos antiquos post partem de isto Sesnando et de suos auctores in presentia de ipsos iudices, et in faciem de ipsos neptos Endulfi, asignauit ipso sagione ipsum uillarem cum auctoribus de Salamiro, post partem de isto Sesnando et de suos 
auctores quomodo illorum ueritas est. Habeant illum firmiter et in perpetum obtineant isti et posteritas illorum. Et isti nepti Endulfi Uermudo et suos heredes comfirmauerunt ipsos term[i]nos quos prouiderunt inter Codais et Parietes de ipsos terminos ad partem de Codais firmiter obtineant. Et qui de nos ausus fuerit aut posteritas nostra iam superius nominati quod in ueritate cognitum est, omnes una pariter consensum preuidimus terminos et ceteros marcos posuimus, firmitatis terminari, firme et stabile esse iubemus. Et qui has diuisiones disrumpere temptauerit aut ausus fuerit marcos ex inde inmutare, aut alium contemptum obposuerit contra hunc factum nostrum uenerit ad irrumpendum, an nos an posteritas nostra, duplet ipsas uillas et insuper dampna secularia aflictus, et pariat auri talentos II $^{\text {os }}$, et uobis perpetim habituros. Condonauerunt ipsos preuisores ut faceremus inter nos istas diuisiones sicut et fecimus, et ordinauerunt illas nos ante illos rouorare, sicut et illi nobis roborauerunt.

Facta diuisio inter Codais et Parietes, era DCCCC ${ }^{\mathrm{a}}{ }^{\mathrm{a}} \mathrm{XXX}^{\mathrm{a}} \ldots$ (Ibíd.: 160-163).

\section{BIBLIOGRAFÍA}

Álvarez Blázquez, José María (1960): La ciudad y los días. Calendario histórico de Vigo, Vigo, Ediciones Monterrey.

Álvarez Blázquez, José María (1980): "Cuadros de Vigo en la Edad Media", en Álvaro Cunqueiro y José María Álvarez Blázquez (coords.), Vigo en su historia, Vigo, Caja de Ahorros Municipal de Vigo, pp. 61-124.

Álvarez Blázquez, José María (1998): Martin Codax, cantor del mar de Vigo, Vigo, Instituto de Estudios Vigueses.

Asensio, Eugenio (1970): Poética y realidad en el cancionero peninsular de la Edad Media, Madrid, Gredos.

Barreiro Somoza, José (1987): El señorío de la iglesia de Santiago de Compostela (siglos IX-XIII), A Coruña, Diputación de A Coruña.

Beltran, Vicenç (1987): Canción de mujer, cantiga de amigo, Barcelona, PPU.

Beltran, Vicenç (2002): "Tópicos y creatividad en la cantiga de amigo tradicional", Santa Barbara Portuguese Studies, VI, pp. 5-21.

Beltran, Vicenç (s. a.): Martin Codax o el poeta intemporal, <http://www.cervantesvirtual.com/ bib_autor/Codax/estudio.shtml>.

Boullón Agrelo, Ana Isabel (1999): Antroponimia medieval galega (ss. VIII-XII), Tübingen, Max Niemeyer.

Boullón Agrelo, Ana Isabel (2013): "Variación e estandarización na toponimia galega", en María Dolores Gordón Peral (ed.), Lengua, espacio y sociedad. Investigaciones sobre normalización toponímica en España, Berlín, De Gruyter, pp. 37-59.

Brea, Mercedes (coord.) (1996): Lírica profana galego-portuguesa, Santiago de Compostela, Xunta de Galicia.

Brea, Mercedes (1999): "Las «cantigas de romería» de los juglares gallegos", en Santiago Fortuño Llorens y Tomás Martínez Romero (coords.), Actes del VII Congrès de l'Associació Hispànica de Literatura Medieval (Castelló de la Plana, 22-26 de setembre de 1997), Castellón de la Plana, Universitat Jaume I, I, pp. 381-396.

Brea, Mercedes y Pilar Lorenzo (1998): A cantiga de amigo, Vigo, Xerais.

Cambón Suárez, Segundo (1957): El monasterio de Santa María de Melón (siglos XII-XIII), tesis doctoral, Santiago de Compostela, Universidade de Santiago de Compostela.

Carré Aldao, Eugenio (1936): Provincia de La Coruña, en Francisco Carreras Candi (dir.), Geografía del Reino de Galicia, II, Barcelona, Alberto Martín. 
Carzolio, María Inés (2002): "Antroponimia servil en el Noroeste hispánico. Los siervos de Celanova, Sobrado y Samos", en Monique Bouren y Pascal Chareille (eds.), Genèse médiévale de l'anthroponymie moderne. Études d'anthroponymie médiévale. VII et ${ }^{e} \mathrm{VII}^{e}$ Rencontres Azay-le-Ferron, 1995-1997, Tours, Université de Tours, pp. 141-213.

Colección diplomática de Galicia Histórica (1901): Santiago de Compostela, Tipografía Galaica, n. ${ }^{\circ}$ CIII.

Correia, Angela (1993): "Sobre a especificidade da cantiga de romaria", Revista da Biblioteca Nacional, VIII, pp. 7-22.

Duby, Georges (1973a): "Structures de parenté et noblesse dans la France du Nord aux XI et XII siècles", en Georges Duby, Hommes et structures du Moyen Âge, Paris, Mouton, pp. 267-285.

Duby, Georges (1973b): "Remarques sur la littérature généalogique en France aux XI ${ }^{\mathrm{e}}$ et XII siècles”, en Georges Duby, Hommes et structures du Moyen Âge, Paris, Mouton, pp. 287-298.

Fernández Guiadanes, Antonio (1998): Cantigas do mar de Vigo: edición crítica das cantigas de Meendinho, Johan de Cangas e Martin Codax, Santiago de Compostela, Xunta de Galicia.

Fernández Rodríguez, Manuel (2004): Toronium. Aproximación a la historia de una tierra medieval, Santiago de Compostela, Instituto de Estudios Padre Sarmiento, CSIC.

Ferreira, Maria do Rosário (1997): "Nomina sunt res? Do poder reificador das designações genéricas no corpus da lírica galego-portuguesa", en Cristina Almeida Ribeiro y Margarida Madureira (coords.), O género do texto medieval, Lisboa, Cosmos, pp. 43-54.

Ferreira Priegue, Elisa (1988): Galicia en el comercio marítimo medieval, A Coruña, Fundación Barrié de la Maza.

Filgueira Valverde, Xosé (1958): "Poesía de santuarios", Compostellanum, 3, pp. 271-286.

Gonçalves, Elsa (1986): "Pressupostos históricos e geográficos à crítica textual no ámbito da lírica medieval galego-portuguesa: (1) "Quel da Ribeira"; (2) A romaria de San Servando", en Actes du Colloque Critique Textuelle Portugaise (Paris, 20-24 octobre 1981), Paris, Fundação Calouste Gulbenkian, pp. 41-53.

González Vázquez, Marta (1996): El arzobispo de Santiago: una instancia de poder en la Edad Media (1150-1400), Sada, Ediciós do Castro.

González Vázquez, Marta y Francisco Javier Pérez Rodríguez (1995): "El sistema antroponímico en Galicia. Tumbo del monasterio de Samos. Siglos VIII al XIII", en Pascual Martínez Sopena (coord.), Antroponimia y sociedad. Sistemas de identificación hispano-cristianos en los siglos IX al XIII, Valladolid, Universidad de Valladolid/Universidade de Santiago de Compostela, pp. 49-71.

Gutiérrez García, Santiago (2008): "Sobre a posible orixe toponímica do apelido Codax", en Mercedes Brea, Francisco Fernández Rei y Xosé Luís Regueira (eds.), Cada palabra pesaba, cada palabra medía. Homenaxe a Antón Santamarina, Santiago de Compostela, Universidad de Santiago de Compostela, pp. 493-501.

Gutiérrez García, Santiago (2010): "Poesía gallegoportuguesa y géneros literarios", Voz y Letra, 21, pp. 11-35.

Herlihy, David (1983): "The Making of the Medieval Family: Symmetry, Structure, and Sentiment", Journal of Family History, 8, pp. 116-130.

López Ferreiro, Antonio (1902): Historia de la Santa A. M. Iglesia de Santiago de Compostela, Santiago de Compostela, Seminario Conciliar Central.

Loscertales de García de Valdeavellano, Pilar (ed.) (1976): Tumbos del monasterio de Sobrado de los Monjes, Madrid, Dirección General del Patrimonio Artístico y Cultural/Archivo Histórico Nacional.

Lucas Álvarez, Manuel (1999): El archivo del monasterio de San Martiño de Fóra o Pinario de Santiago de Compostela, II, Sada, Ediciós do Castro/Seminario de Estudos Galegos.

Maia, Clarinda Azevedo (1997): História do galego-português. Estado linguístico da Galiza e do Noroeste de Portugal desde o século XIII ao século XVI (Com referência à situação do galego moderno), Lisboa, Fundação Calouste Gulbenkian. 
Mattoso, José (1980): A nobreza medieval portuguesa, a família e o poder, Lisboa, Estampa.

Mattoso, José (1985a): Ricos-homens, infanções e cavaleiros. A nobreza medieval portuguesa nos séculos XI e XII, Lisboa, Guimarães Editora.

Mattoso, José (1985b): Identificação de um país. Ensaio sobre as origens de Portugal 10961325, Lisboa, Estampa.

Mattoso, José (1993): "Livros de Linhagens", Giulia Lanciani y Giuseppe Tavani (coords.), Dicionário da literatura medieval galega e portuguesa, Lisboa, Caminho, pp. 419-421.

Michäelis de Vasconcelos, Carolina (1905): Cancioneiro da Ajuda, Lisboa, Imprensa Nacional Casa da Moeda.

Monteagudo, Henrique (1998): "Cantores de santuario, cantares de romaría", en Congreso "O mar das cantigas", Santiago de Compostela, Xunta de Galicia, pp. 99-127.

Monteagudo, Henrique (2014): A nobreza minhota e a lírica trobadoresca na Galicia da primeira metade do século XIII: a personalidade histórica do trobador Johan Soayrez Somesso; os trobadores Afonso Soarez Sarraça e Estevan Fayan, Noia, Toxosoutos.

Moralejo Lasso, Abelardo (1977): Toponimia gallega y leonesa, Santiago de Compostela, Pico Sacro.

Mussons, Anna Maria (1996): "Los trovadores en los últimos años del siglo XIII. Ayras Nunez y la romería de Sancho IV", en Carlos Alvar y José Manuel Lucía Megías (eds.), Actas del Congreso Internacional "La literatura en la época de Sancho IV" (Alcalá de Henares, 21-24 de febrero de 1994), Alcalá de Henares, Universidad de Alcalá de Henares, pp. 232-233.

Nunes, José Joaquim (1973): Cantigas d'amigo dos trovadores galego-portugueses, Lisboa, Centro do Livro Brasileiro.

Oliveira, António Resende de (1994): Depois do espectáculo trovadoresco, Lisboa, Colibri.

Oliveira, António Resende de (2001): O trovador galego-portugués e o seu mundo, Lisboa, Notícias.

Portela Silva, Ermelindo (1976): La región del Obispado de Tuy en los siglos XII a XV: una sociedad en la expansión y en la crisis, Santiago de Compostela, El Eco Franciscano.

Portela Silva, Ermelindo (1981): La colonización cisterciense en Galicia (1142-1250), Santiago de Compostela, Universidad de Santiago de Compostela.

Portela, Ermelindo y María del Carmen Pallares (1993a): "Algunos problemas relativos a la evolución de las estructuras familiares en la nobleza", en De Galicia en la Edad Media. Sociedad, espacio y poder, Santiago de Compostela, Xunta de Galicia, pp. 261-276.

Portela, Ermelindo y María del Carmen Pallares (1993b): "Aristocracia y sistema de parentesco en los siglos centrales de la Edad Media: el grupo de los Traba", Hispania. Revista Española de Historia, 53, pp. 823-840.

Portela, Ermelindo, y Pallares, María del Carmen (1995): "El sistema antroponímico en Galicia. Tumbos del monasterio de Sobrado. Siglos IX a XIII", en Pascual Martínez Sopena (coord.), Antroponimia y sociedad. Sistemas de identificación hispano-cristianos en los siglos IX al XIII, Valladolid, Universidad de Valladolid/Universidade de Santiago de Compostela, pp. 21-47.

Rei, Maxi (2004): "Referencias documentais ó concello de Abegondo durante a Alta Idade Media”, Anuario Brigantino, XXVII, pp. 179-198.

Ron Fernández, Xosé Xabier (2005): "Carolina Michaëlis e os trobadores representados no Cancioneiro da Ajuda", em Mercedes Brea (coord.), Carolina Michaëlis e o Cancioneiro da Ajuda, hoxe, Santiago de Compostela, Xunta de Galicia, pp. 121-188.

Ron Fernández, Xosé Xabier (2016): "Documentatio nomina tropatorum (I). Unha nova hipótese sobre o trobador Johan Nunez Camanez e sobre o apelido de Martin Codax", en Elvira Fidalgo Francisco, Esther Corral Díaz y Pilar Lorenzo Gradín (eds.), Cantares de amigos. Estudos en homenaxe a Mercedes Brea, Santiago de Compostela, Universidade de Santiago de Compostela, pp. 769-778.

Sánchez Bargiela, Rafael (1999): "Vigo na Idade Media", en Antonio de la Peña Santos et alii, Historia de Vigo, Vía Oleiros, Láctea Editorial, pp. 86-171. 
Santiago y Gómez, José de (2005 [1895]) : Historia de Vigo y su comarca, Pontevedra, Diputación de Pontevedra.

Souto Cabo, José António (2012): Os cavaleiros que fizeram as cantigas: aproximação às origens socioculturais da lírica galego-portuguesa, Niterói, Editora da Universidade Federal Fluminense.

Tavani, Giuseppe (1986): A poesía lírica galego-portuguesa, Vigo, Galaxia.

Tavani, Giuseppe (1992): A poesía de Airas Nunez, Vigo, Galaxia.

Tavani, Giuseppe (1998): "Aínda sobre Martin Codax e Mendinho", en Congreso O Mar das Cantigas, Santiago de Compostela, Xunta de Galicia, pp. 43-58.

Torres Luna, María Pilar de (dir.) (1986): Geografía de Galicia. II, Población y poblamiento, A Coruña, Xuntanza.

Ventura, Leontina (1992): A nobreza de corte de Afonso III, Coimbra, Universidade de Coimbra.

Vieira, Yara Frateschi (1999): En cas dona Maior: os trovadores e a corte senhorial galega no século XIII, Santiago de Compostela, Laiovento.

Weiss, Julian (1988): "Lyric Sequences in the Cantigas d'amigo", Bulletin of Hispanic Studies, LXI, pp. 21-37.

Weiss, Julian (1997): "On the Conventionality of the Cantigas d'amor", La Corónica, 26, pp. 225-245

Ziegler, Vickie L. (1975): The Leitword in Minnesang: Stylistic Analysis and Textual Criticism, University Park, Pennsylvania State University Press.

Zumthor, Paul (1972): Essai de poétique médiévale, Paris, Seuil.

Fecha de recepción: 2 de julio de 2016

Fecha de aceptación: 13 de septiembre de 2016 